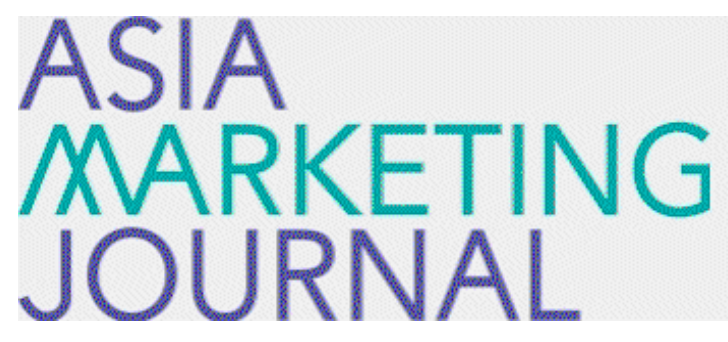

ASIA MARKETING JOURNAL

Volume 22 | Issue 2

Article 4

$7-31-2020$

\title{
Vying with IKEA: HANSSEM's Competitive Advantage at Marketing Frontier
}

Sang Yong Kim

Seung Min Lee

Follow this and additional works at: https://amj.kma.re.kr/journal

Part of the Marketing Commons

\section{Recommended Citation}

Kim, Sang Yong and Lee, Seung Min (2020) "Vying with IKEA: HANSSEM's Competitive Advantage at Marketing Frontier," Asia Marketing Journal: Vol. 22 : Iss. 2 , Article 4.

Available at: https://doi.org/10.15830/amj.2020.22.2.87

This Article is brought to you for free and open access by Asia Marketing Journal. It has been accepted for inclusion in Asia Marketing Journal by an authorized editor of Asia Marketing Journal. 


\title{
Vying with IKEA: HANSSEM's Competitive Advantage at Marketing Frontier*
}

\author{
Sang Yong Kim** \\ Seung Min Lee***
}

HANSSEM is a furniture company that leads the market of residential space in Korea. The goal of this case study is to focus on how HANSSEM copes with IKEA, the world's largest furniture retailer after entering the Korean market in December 2014. IKEA's entry into Korea is possible to destroy the existing orders in the retail industry and reduce the profit of incumbent local players by realigning industry relationships. However, HANSSEM achieved rapid growth with the largest market share in the furniture market through its internal capabilities.

The authors propose the main success factors in three ways: (1) residents-database including apartment floorplans in Korea, (2) high-quality human services provided by construction and A/S (After-sales Service), (3) channel diversification that provides comprehensive consultations (e.g., flagship stores, home shopping channels, stores in marts, and interior dealers).

Especially, there have been various consumer needs in Korean market, such as creating their own stylish space economically. HANSSEM meets customer's needs by reinforcing the space-package (complete-interior is provided to customer in a package rather than combining individual piece of furniture) and opening showrooms, which makes customers freely experience the products and receive detailed consultations on interior designs by alleviating customers' difficulties in decorating their homes.

Based on HANSSEM's outstanding activities and new investments, we look forward to seeing that HANSSEM will achieve its ultimate goal of maintaining the position of number one furniture company by attaining customer satisfaction through higher quality in Korea.

Keywords: Furniture Industry, Database of Residents, Human Services, Channel Diversification, Showrooms

This research is financially supported for the corresponding author by a Korea University Grant, and initiated during the first author's sabbatical semester.

** Professor, Korea University Business School, Korea (sangkim@korea.ac.kr)

*** Research Professor, Korea University Business School, Korea(flyfar@korea.ac.kr), Corresponding Author 


\section{Introduction}

The furniture block in Nonhyeon-dong, Gangnam-gu, Seoul, South Korea, is filled with many furniture showrooms that resemble model houses. These showrooms have various types of living spaces such as book rooms, family room, newlywed couple space, and kid's zone. Instead of randomly displaying furniture for sale, the showroom displays how the various pieces of furniture are combined. The best thing for the customers is the price and quality of furniture can be compared in one block.

Who started the showroom at Nonhyeon-dong Furniture Street? It was HANSSEM; the market-leading furniture company in Korea. As pointed out by Kim (2019), HANSSEM has introduced a showroom culture on Nonhyeondong furniture street, making it possible for customers to crowd the block despite the recession of the retail industry.

HANSSEM was originally a kitchen furniture company founded in Korea in 1970. However, it has grown into a full-service interior company with the mission of "contributing to the advancement of humanity through improving living space", supplying household accessories and fabric products as well as kitchen furniture. This growth has improved interior design expertise in various residential areas. Due to expertise in the furniture market for the past decade, showrooms have opened that provide services that allow customers to freely inquire about interior design and experience the product furniture in person. In addition to Nonhyeondong, showrooms also opened at Bangbae, Busan Centrum, and Bundang.

As a consequence of the above, HANSSEM has achieved rapid growth with sales of KRW 2.625 trillion in 2017 (see Figure1), and the largest market share in the furniture market in Korea. This performance is particularly noteworthy because IKEA, the world's largest furniture company, entered the Korean market in December 2014, negatively affecting incumbent furniture makers in the domestic market.

Previous studies have shown that the entry of large global retailers (e.g., Walmart) can destroy existing orders within the retail industry and decline the profit of incumbent local players by reshaping industry relationships (Aitken and Harrison 1999; Gielens, Van de Gucht, Steenkamp, and Dekimpe 2008). Regardless of these external issues, HANSSEM has shown steady growth. This research suggests that the success of HANSSEM's strategy is threefold: (1) its residents-database including $80 \%$ of all apartment floorplans in Korea, (2) high-quality human services provided in installment and $\mathrm{A} / \mathrm{S}$ (After-sales Service), (3) channel diversification to provide comprehensive consultations (e.g., flagship stores, home shopping channels, stores in marts, and interior dealers).

The purpose of this case study is to investigate how HANSSEM maintains the position of 
〈Figure 1〉 HANSSEM's Annual Sales Revenue and Operating Income

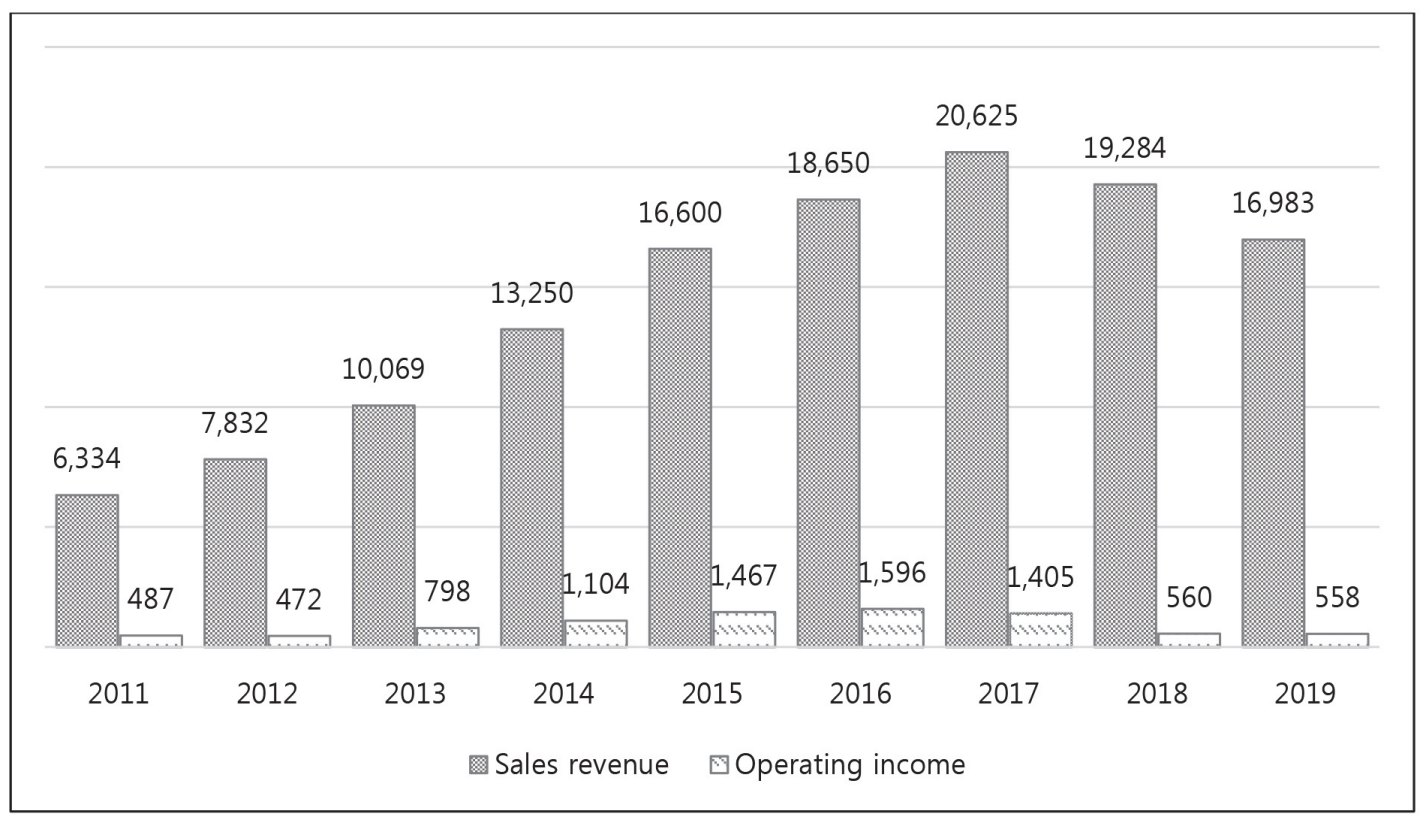

\begin{tabular}{|c|c|c|c|c|c|c|c|c|c|}
\hline & 2011 & 2012 & 2013 & 2014 & 2015 & 2016 & 2017 & 2018 & 2019 \\
\hline $\begin{array}{c}\text { Profit } \\
\text { Margin }\end{array}$ & 5.51 & 5.04 & 6.09 & 6.54 & 6.71 & 6.59 & 4.65 & 4.66 & 2.52 \\
\hline
\end{tabular}

Unit (Sales revenue, Operating income): One hundred million Won

Unit (Profit margin): \%

(Source: HASSEM internal source)

※ Sales revenue and operating income declines in 2018-2019 due to the decrease in housing transaction volume in the real estate market. However, HANSSEM continues to be in a first place in furniture market in South Korea (in terms of sales share)

number one furniture company in Korea even with the presence of IKEA, the world's largest furniture retailer. This case study consists as follows: an overview of the furniture market environment, HANSSEM's key success factors, and conclusions on the strategic direction for the future.

\section{Furniture Market Environment}

\subsection{Customers}

Customers have increased their needs to decorate their homes as the income level of Korean customers has risen since the mid-2000s. In 2014, as IKEA entered the Korean market, their needs increased further. Although Korean 
customers have become more interested in decorating their homes than before, they still have insufficient knowledge about how to decorate and use their homes due to the lack of education on the interiors of their homes. For example, even if customers want to decorate their home in a trendy Nordic style, unfortunately, they don't know what kind of large furniture is suitable for their home. Another problem is that they are struggling to figure out if 'big' furniture fits at home.

Nevertheless, in response to these customer needs, furniture companies offer space utilization and home decoration consultations to help customers purchase with confidence. In addition, a new term called "home furnishings" comes out in the Korean language, which means decorating more than furniture (i.e., the home). The furnishing market consists of furniture and interior accessories. In the furniture industry, according to Bang (2017), the Korean furniture industry is estimated at approximately KRW 10 trillion in 2019 and expects to double in size from its present level by 2025. Moreover, due to the active upheaval of the future real estate market, the demand for furniture and interior decoration is also expected to soar. Thus, the furniture prospects for the home furniture markets have a bright future.

\subsection{Competitors}

The major competitors in the furniture market are Hyundai LIVART and IKEA.' ${ }^{1)}$ LIVART, one of the major domestic competitors, has a large customer base in the office furniture market. With the aims of expanding the market to $\mathrm{B} 2 \mathrm{C}$, it has traditionally created fixed sales of office furniture from its Hyundai group affiliates of the B2B furniture market, resulting in a securing a customer base and retaining strengths. Furthermore, as a subsidiary of the Hyundai department store, the image has been strengthened with the 'high end' strategy by utilizing the advanced image of the Hyundai department store. In 2019, LIVART launched the Ceramic Kitchen Furniture 'Terra Series', which included products using FLORIM stones from Italian premium products.

Not only that, but it is a notable example of differentiation because LIVART exhibited artworks and cultural spaces such as cafes and galleries. Extending beyond a space where furniture products are displayed and sold, LIVART is the first to introduce a large-scale lounge-type exhibition hall where customers can relax and enjoy various cultural experiences and are gradually expanding the customers from the B2B to B2C. Additionally, since 2018, LIVART has been aggressively investing in factories and increasing the production capacity

1) Hyundai LIVART is the second-largest furniture company in South Korea, followed by IKEA ( $3^{\text {rd }}$ place) in terms of sales share in 2019 
of its own products. Specifically, with the acquisition of Hanwha L\&C, LIVART recently entered the construction materials market. As a result, it is worth noting that the number two Korean furniture company has played an important role in the furniture and building materials sector. Fortunately, LIVART is not directly threatened by IKEA since LIVART mainly focuses on B2B business whereas IKEA does on B2C as a new entrant in Korea.

IKEA is a global home furnishing company which is another competitor to HANSSEM. The first IKEA in Korea entered Gwangmyeong-si, Gyeonggi-do, in december 2014. It aimed to add five stores before 2020 and continued to opened at stores in Giheung in 2019 and Busan in early 2020. Moreover, IKEA officially launched

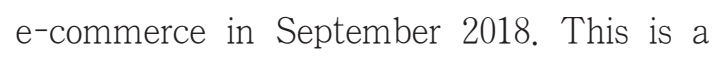
long-term growth strategy by diversifying customer contacts by multiple channels.

When IKEA first announced its entry into the Korean market, there were concerns about whether it would receive a favorable response from Korean customers or it would soon withdraw from the Korean market due to anxiety over its "DIY" (Do-It-Yourself) system, which is not familiar to Korean customers. Although IKEA is relatively inexpensive, it sells DIY furniture that requires self-assembly rather than finished products. However, it turned out that such concerns are invalid. Korean customers quickly became accustomed to its DIY furniture assembly system and responded positively to IKEA's reasonable prices.

Such IKEA's successful entry to the Korean market is the consequence of the fact that there have been various customer needs such as creating their own space due to the rise in the number of single-person households and desire to create their own stylish space economically. IKEA meets customers' needs by aligning their inherent "cheap-chic" brand identity of practical and aesthetic furniture with the changing trend in customers who value cost-effectiveness. Thus, in the home furnishing craze, demand has increased for trendy and affordable furniture, and IKEA was considered the best way to meet this demand. Furthermore, the popularity of IKEA can be attributed to stores with a variety of shopping contents. As a result, customers have a positive attitude towards IKEA, not just a

〈Table 1〉 Key Business Area of Major Players

\begin{tabular}{c|c|c|c|c|c|c|c|c|c}
\hline & $\begin{array}{c}\text { Remodeling } \\
\text { Construction }\end{array}$ & $\begin{array}{c}\text { Kitchen } \\
\& \text { \&ath } \\
\text { Appliances }\end{array}$ & $\begin{array}{c}\text { Regular } \\
\text { Furniture }\end{array}$ & $\begin{array}{c}\text { Office } \\
\text { Furniture }\end{array}$ & $\begin{array}{c}\text { Built-in } \\
\text { Appliances }\end{array}$ & $\begin{array}{c}\text { Household } \\
\text { Goods }\end{array}$ & Mattress & $\begin{array}{c}\text { Home } \\
\text { Quarantine }\end{array}$ & $\begin{array}{c}\text { Marine } \\
\text { Furniture }\end{array}$ \\
\hline HANSSEM & 0 & 0 & 0 & 0 & 0 & 0 & 0 & 0 & - \\
\hline LIVART & 0 & 0 & 0 & 0 & 0 & 0 & 0 & - & 0 \\
\hline IKEA & - & 0 & 0 & - & - & 0 & 0 & - & 0 \\
\hline
\end{tabular}


place to buy furniture, but also a shopping area where they can spend their meals and time.

\subsection{Company}

One of the most notable recent changes in the furniture market in Korea is the introduction of a so-called 'participatory design system' through collaboration with interior designers and design research centers. As such, HANSSEM is also launching new systems or campaigns under the name "HANSSEM Rehouse" to meet these trends.

'HANSSEM Rehouse' is focused on two features of the market trends. First, since 2014, it has been reinforcing the "space package product" as a new market driver, by suggesting customer lifestyle in terms of space. A "space package" is a product offering kitchen, windows, bathroom, and floors in a package; a completeinterior (as known as total interior) is provided to customers in a package rather than combining individual pieces of furniture by themselves, thereby relieving customers of difficulties regarding decision making.

Second, offline stores are becoming more like showrooms in the furniture market. Since a growing number of online channels are popular in shopping, the furniture industry has been dedicated to meeting their needs for what furniture will actually look like when placing furniture in spaces such as living rooms, bedrooms, dining rooms, and so on. In this regard, offline stores are shaping into showrooms. Accordingly,

\section{〈Figure 2〉 Channel Diversification of HASSEM}

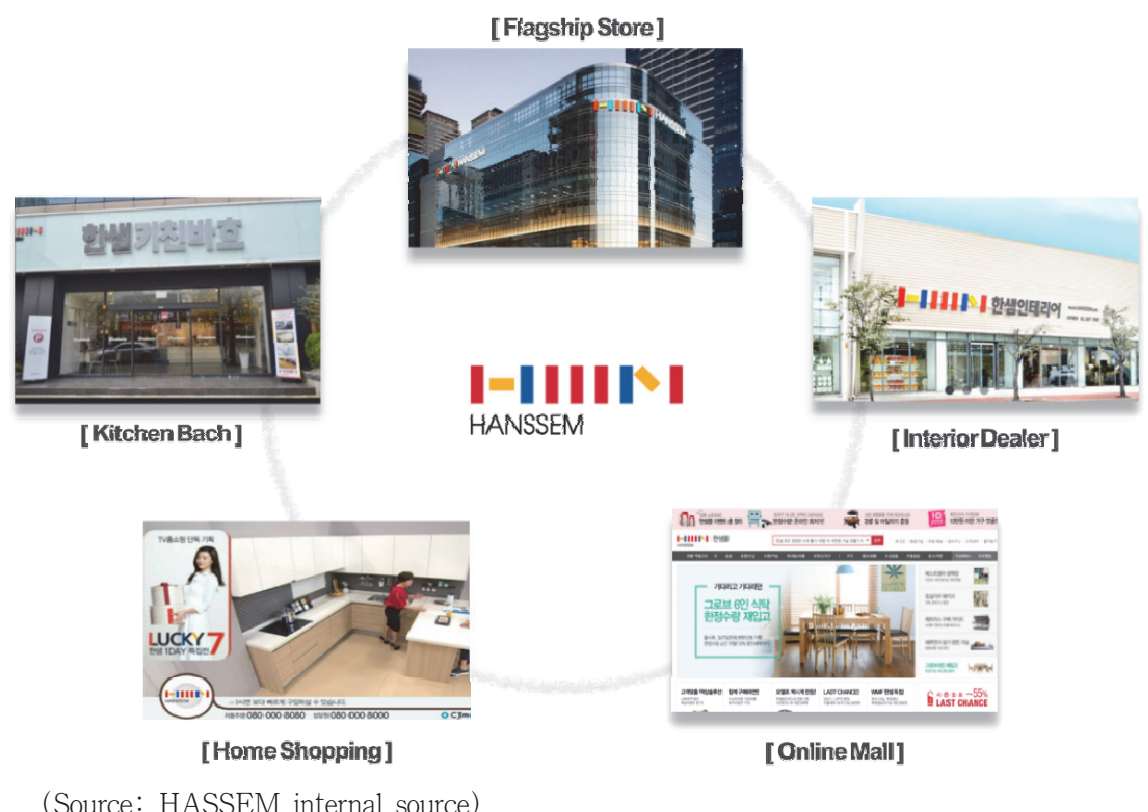


HANSSEM has established nine flagship stores or showrooms (Bangbae, Nonhyeon, Bundang, Jamsil, Busan Centum, Mokdong, Daegu Beomeo, Suwon, and Sangbong) to provide the convenience for customers to experience the product freely and check the functions directly (See Figure 2).

In accordance with this trend in the furniture market, we need to observe what efforts HANSSEM is actually being made. In the next section, we will examine the key success factors or the competitive advantages of HANSSEM in detail.

\section{HANSSEM's Competitive Advantages}

\subsection{Database of apartment floorplans}

HANSSEM redefined the concept of "lifestyle" to meet the needs of people decorating their homes as we discussed in the previous section. It offers the spaces in line with one's life cycle and personal characteristics such as newlywed couple space, kids' zone, an elderly couple, and book room. Such various 'lifestyle' spaces widen the customer range of ages, not by simply displaying furniture for sale to specific agegroups or segments. Then, it has enhanced its 'space style package' products that customers can easily understand and choose. The company suggests the 'spaces' suitable for the customer's living environment and has created packaged products to facilitate customer selection.

With the goal of easily and conveniently providing these space package products to customers, HANSSEM established a database of residents in South Korea that have accumulated over 50 years. In particular, $80 \%$ of all apartment floorplans $^{2}$ in Korea were acquired and converted into data, while other companies in the furniture industry ignored the importance of the database of apartment floorplans. The database of HANSSEM is a unique competitive advantage since no other player in the furniture industry has. Thus, this database can enable HANSSEM to work at the harmony of the interior and furniture to the customer's living space with the standardization.

For customers living in Samho Apartment $84 m^{2}$, Bangbae-dong, Seoul, for example, HANSSEM has packaged the entire furniture process from placing the furniture on the floor plan to creating the optimal space for customers. In terms of logistics as well, this has the advantage of not only reducing defects but also minimizing complaints caused by discrepancies between what the customer expected and the actual appearance. In addition, for customers

2) In Korea, apartment floorplans can be accessed publicly through construction companies when they promote their apartment buildings through model houses at the very early stage of the selling the apartments. 
who desire professional consultation, HANSSEM has built a system called "HANSSEM Home Planner" to offer consultations on interior-related questions from ordering to construction.

Furthermore, the database of apartment floorplans will be a great help as the company launches AR (Augmented Reality) with emerging technologies. It can show customers the furniture arrangement in a virtual space remarkably similar to their real living space.

\subsection{Control capability in construction and A/S (After-sales Service)}

One of the reasons for HANSSEM's high profitability and customer attraction is that it provided a centralized control function by building an integrated system in terms of installation and A/S (After-sales Service). It has been cooperating with 4,500 construction engineers, which has the largest number of construction engineers compared to competitors, to provide customers with faster and higher quality human services by covering entire Korea, including Jeju Island. Through these efforts, HANSSEM minimizes lead times (time from sales order to production completion) and defects. In other words, it can complete kitchens and bathrooms in 7 days with the company's internal guidelines for construction engineers. Considering that the average length of the construction period in the developed countries such as the USA and European nations ranges from about fifteen days to one month, the HANSSEMS's lead time is an extraordinary achievement. Furthermore, as an alternative to setting general architectural standards for all customers, HANSSEM conducted construction according to the customer's lifestyle as well as the customer's preferred date, holiday, and vacation schedule. In terms of $\mathrm{A} / \mathrm{S}, 300$ employees are working as members directly belonged to the $\mathrm{A} / \mathrm{S}$ team in headquarter. Additionally, A/S team collects customers' complaints and regularly held quality improvement meetings. This assures the company's higher control capability. Also, it has positive influence on customer satisfaction, perceived value, and post-purchase intention, similar to the findings of notable success points as shown in previous research (e.g., Kuo, Wu, and Deng 2009). With the excellence in controllability of human resources for construction and after-sales services, HANSSEM paves the way to dominate the market even for the future.

\subsection{Channel diversification: Online and offline channels}

The rapid sales growth of HANSSEM was due to the diversification of marketing channels. This is consistent with previous research that marketing diversification plays an important role in increasing firm sales (Coelho, Easingwood, and Coelho 2003). Most importantly, it differentiates channels by price, 
from low- and medium-priced line dealers to those that handle premium product offerings such as Kitchen Bach.

In addition, the company has secured a variety of channel types including online and offline vendors. For example, it possesses flagship stores, home shopping channels, stores in marts, and interior dealers (see Figures 2 and 3). The flagship stores are located at numerous hubs, including Bangbae, Busan Centum, Nonhyeon, and Bundang. Each flagship store is providing a space for customers to freely ask consultations and experience products.

In addition, HANSSAM opened a small-sized store at marts and interior dealers and it provides more access to people who can easily receive comprehensive consultation on interior design. This is intended to alleviate customers' difficulties with the ambiguous knowledge of interior design.

Furthermore, for the first time in the furniture industry, HANSSEM has used the TV home shopping channels to help customers order or request consultation with the nearest dealers. Particularly, this is another smart diversification effort of the marketing channel with avoiding competition between the dealer and the home shopping channel. By not directly selling the

〈Figure 3〉 HASSEM's Flagship Store at Bangbae

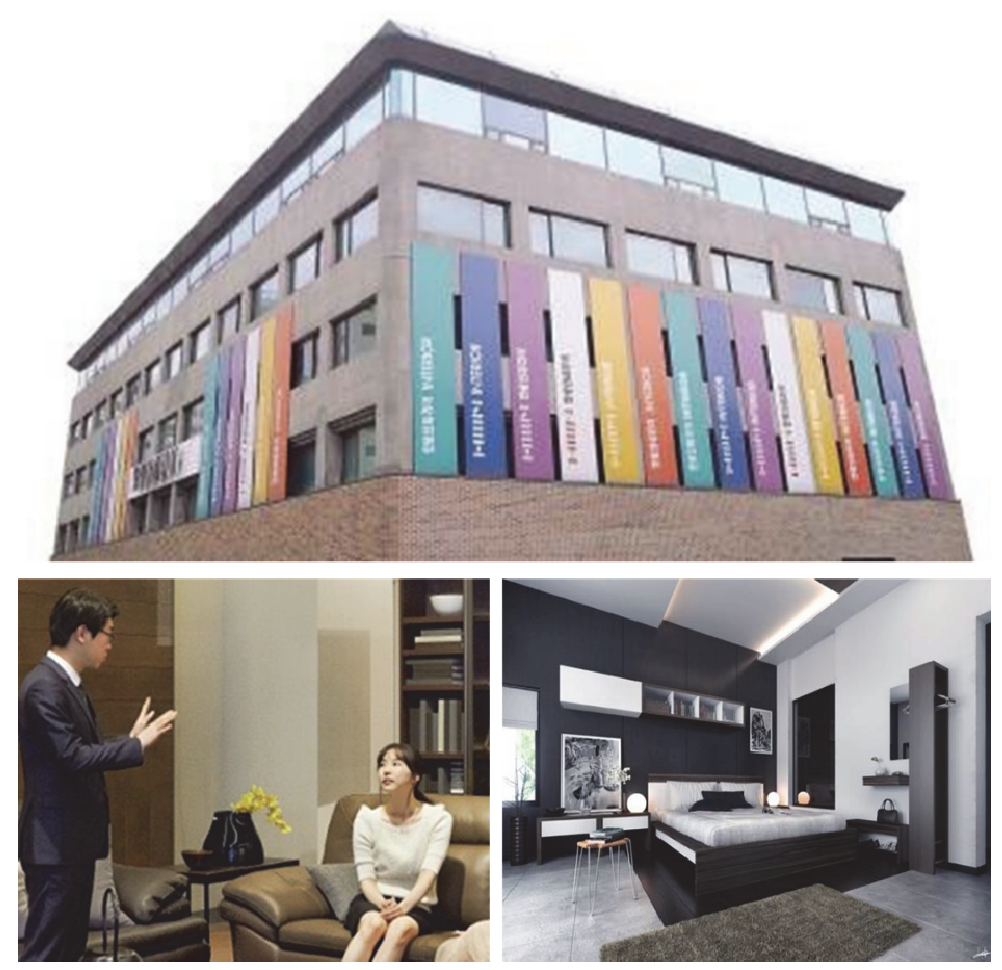

(Source: HASSEM internal source) 
products, HANSSEM can maintain a mutually beneficial relationship with the dealers as well as with the TV home shopping channels.

\section{Conclusion}

The furniture market in South Korea confronted difficult and competitive environments. One of the difficulties was the decrease in demand for household furniture due to population decline. Another was changing customer tastes. Customers pursue whole house decorations as known as 'home interiors' rather than matching each piece of furniture in rooms. This new customer trend attracts small and medium-sized companies entering the local furniture markets. Not only that, but the global furniture retailer of IKEA also joined in South Korea, it severely accelerated the competitive market environment. Interestingly, HANSSEM and IKEA were successful together in the Korean market. IKEA has successfully settled down in the Korean market, while HANSSEM has successfully increased the sales volume even after IKEA entered in 2014. As a result, the two companies expanded the furniture market volume in the furniture industry by increasing people's interest in the interior.

As with other successful Korean companies, such as Dongwon Systems and Korea Jinseng Corporation, which were excellent in the spirit of marketing frontier (Jun, Kim, and Koo
2018; Koo, Kim, and Jun 2018), HANSSEM was also committed to building brand equity, developing new markets, researching customerdata, and harmoniously managing marketing channels. Specifically, it foresees its own negative environments in advance and responds steadily to maintain its first-mover advantage in the domestic market. We suggested that HANSSM's strategy of the main success is due to three factors: 1) database of residents including $80 \%$ of all apartment floorplans in Korea, 2) control capability in construction and after-sales service, and 3) diversification of marketing channels. These three factors can be considered as the firm's specific resources. Such resources maintain sustainable value in the market, which is difficult to replicate by other firms in terms of the resource-based view (Mahoney and Pandian 1992).

HANSSEM responded to the needs of customers in line with the trend. It suggested to customers that it is not a single item, but a package that encompasses all flooring wallpaper, lighting, and home appliances, so that they have less trouble in completing home styling easily. Showrooms opened the place where customers can freely experience products and consultations on interior design, alleviating the difficulties of decorating their homes. Moreover, HANSSEM has established a database of residents and apartment floorplans in South Korea.

Second, HANSSEM has built a relationship 
network with construction engineers. And it also tries to connect the existing associated businesses such as moving, cleaning, courier, and furniture or mattress rental services (Seo 2019). Furthermore, the human resources for after-sales service are all directly employed by the headquarter of the company. As a consequence, these networks guarantee the company's higher control capability for the highest customer satisfaction.

Third, by securing various marketing channels including online and offline suppliers, it expanded the range of customer contacts and achieved the synergy by avoiding the possible conflicts among channel members.

Based on these outstanding activities and strategic preparation for the future, HANSSEM achieved customer satisfaction through high quality and service innovation, and we still expect to continue to be the best domestic 'household furniture' company in the future.

〈Received March 10. 2020〉

〈Accepted July 21. 2020〉

\section{References}

Aitken, B. J., \& Harrison, A. E. (1999). Do domestic firms benefit from direct foreign investment? Evidence from Venezuela. American Economic Review, 89(3), 605618.
Bang, G. A. (2017). HANSSEM vs. IKEA, What is your strategy?. bizwatch, (accessed February 20, 2020), [available at http:// news.bizwatch.co.kr/article/consumer/2017 /10/13/0018].

Coelho, F., Easingwood, C., \& Coelho, A. (2003). Exploratory evidence of channel performance in single vs multiple channel strategies. International Journal of Retail \& Distribution Management, 31(11), 561573.

Gielens, K., Van de Gucht, L. M., Steenkamp, J. B. E., \& Dekimpe, M. G. (2008). Dancing with a giant: The effect of Wal-Mart's entry into the United Kingdom on the performance of European retailers. Journal of Marketing Research, 45(5), 519-534.

Jun, M., Kim, S. Y., \& Koo, K. R. (2018). Differentiated B2B marketing strategy of Dongwon Systems, the No.1 packaging solution company in Korea. Asia Marketing Journal, 20 (3), 1-15.

Kim (2019). "HANSSEM to vie with IKEA" Nonhyun-dong Furniture Street Revitalized as Showroom. Chosunilbo, (accessed February 20, 2020), [available at https://biz.chosun. com/site/data/html_dir/2019/11/11/2019 111100312.html].

Koo, K. R., Kim, S. Y., \& Jun, M. (2018). Strengthening market position through branding "CheongKwanJang"- the case of Korea Ginseong Corporation. Asia Marketing Journal, 20(2), 85-98. 
Kuo, Y. F., Wu, C. M., \& Deng, W. J. (2009). The relationships among service quality, perceived value, customer satisfaction, and post-purchase intention in mobile valueadded services. Computers in Human Behavior, 25(4), 887-896.

Mahoney, J. T., \& Pandian, J. R. (1992). The resource based view within the conversation of strategic management. Strategic Management Journal, 13(5), 363-380.

Seo, J.Y. (2019), HANSSEM leads business diversification. JoongAng Ilbo, (accessed February 20, 2020), [available at https:// news.joins.com/article/23399040]. 